\title{
Stress intervention and disease in African American lupus patients: The balancing lupus experiences with stress strategies (BLESS) study
}

\author{
Edith M. Williams ${ }^{1 *}$, Diane Kamen ${ }^{2}$, Megan Penfield ${ }^{3}$, James C. Oates ${ }^{2,4}$ \\ ${ }^{1}$ Institute for Partnerships to Eliminate Health Disparities, Arnold School of Public Health, University of South Carolina, Columbia, \\ USA; *Corresponding Author: willi425@mailbox.sc.edu \\ ${ }^{2}$ Division of Rheumatology and Immunology, Department of Medicine, Medical University of South Carolina, Charleston, USA \\ ${ }^{3}$ Institutional Assessment and Compliance, University of South Carolina, Columbia, USA \\ ${ }^{4}$ Medical Service, Ralph H. Johnson VA Medical Center, Charleston, USA
}

Received 26 November 2013; revised 28 December 2013; accepted 7 January 2014

Copyright (c) 2014 Edith M. Williams et al. This is an open access article distributed under the Creative Commons Attribution License, which permits unrestricted use, distribution, and reproduction in any medium, provided the original work is properly cited. In accordance of the Creative Commons Attribution License all Copyrights (C) 2014 are reserved for SCIRP and the owner of the intellectual property Edith M. Williams et al. All Copyright (c) 2014 are guarded by law and by SCIRP as a guardian.

\section{ABSTRACT}

Very little is known about the impact of psychosocial stress on underlying biological mechanisms in African American lupus patients, although African American women display the highest rates of lupus. Due to the exposure of African Americans to a unique trajectory of stressors throughout the life course, it may be critical to understand the relationship between psychosocial stress and underlying biological mechanisms that influence disease activity and pathology in this high risk group. To begin to fill this research void, an evidence-based self-management program was piloted among a cohort of African American lupus patients participating in a SLE database project at the Medical University of South Carolina (MUSC). To assess disease activity, during each clinic visit, a history is obtained, and physical examination, phlebotomy, and urine collection are performed. SLE Disease Activity Index (SLEDAI) and Systemic Lupus International Collaborating Clinics/American College of Rheumatology (SLICCIACR) Damage Index (SDI) scores are assessed at each visit. Disease data corresponding with data collection timeframes for each participant were extracted from the MUSC SLE Database to assess the effectiveness of the program. Several differences were observed between the intervention and control groups on symptoms pertaining to lupus activity, and many of these differences had large effect sizes. Our findings can be rapidly trans- lated into improved delivery of health care and targeted trials/interventions with relevance to health disparities, and if widely implemented, morbidities and mortality related to lupus could be drastically reduced in African-Americans.

\section{KEYWORDS}

\section{SLE; African Americans; Self Management;} Stress; Lupus; Disease Activity

\section{INTRODUCTION}

Systemic lupus erythematosus (SLE) is a chronic inflammatory rheumatic disease that is characterized by autoantibody production and multiple organ system involvement, including a high prevalence of polyarthritis [1-4]. SLE can lead to an array of clinical presentations, making it difficult to diagnose early [5]. In the United States, over the past four decades, SLE incidence has increased and claims one of the highest mortality rates among rheumatic diseases [6,7]. Treatment for SLE patients can be complex and potentially toxic, yet some of these treatments have been shown to improve prognosis [8]. SLE can result in extreme joint discomfort, fatigue, and diminished psychosocial functioning [9-12]. Complications from the treatment of SLE are also common, especially infections due to the use of immune suppressing medications, and adverse effects of corticosteroid use such as weight gain, osteoporosis, osteonecrosis, and accelerated atherosclerosis $[13,14]$. Many of these side effects can lead to significant functional and emotional challenges [12]. Patients often experience a high degree 
of psychological symptoms, including anxiety, depression, mood disorders, and decreased health-related quality of life [15-20].

African-Americans have a 3-fold increased prevalence of SLE, generally develop SLE at an earlier age, experience more severe disease activity, frequency of complications, severity and overall prognosis of SLE, and have increased SLE-related morbidity and mortality compared with whites [21-30]. In addition to managing disease-specific stressors, it has been suggested that African-Americans are exposed to a unique set of risk factors that lead to a pattern of cumulative disadvantage over time. High rates of unemployment, poverty, violent crime, incarceration, and homicide among African-American adults reflect this accumulation of disadvantage at multiple transition points during their development and across the life course [31-43]. It is highly likely that early childhood exposure to segregated, economically impoverished neighborhoods created by institutionalized racism adversely affects child health and growth and sets the black child on a low education and economic trajectory that increases the risk of poor physical and mental health in adulthood [34]. Additional stressors include deprivation of resources and facilities, differential exposure to health risks in the physical environment because of economically disadvantaged neighborhoods and poor quality housing, higher costs of goods and services in deprived areas, as well as roles of social networks and social capital, which often give rise to peer pressure against academic achievement and in support of crime and substance use [31,32, 35,36]. Due to the exposure of African-Americans to a unique trajectory of stressors throughout the life course, it may be critical to address modifiable risk factors for SLE that may be further exacerbated by this trend in an effort to improve health status and reduce health disparities in this high risk group.

A large body of evidence has shown that health-promoting programs in stress management have been successful in helping people improve their health practices and related health conditions [37]. Such techniques have also resulted in short-term improvement in pain, fatigue, psychological function, and perceived physical function among persons with SLE $[44,45]$. Although there is no generally accepted self-management program available for SLE [18], two programs that have been shown to be successful in improving conditions in patients with arthritis are the Arthritis Self-Management Program (ASMP) and the generic Chronic Disease Self-Management Program (CDSMP). Each program incorporates six weeks of peer-led sessions ranging in disease-specific and more general self-help content. Both programs have demonstrated significant improvements in health distress, selfreported global health, and activity limitation, with trends toward improvement in self efficacy and mental stress management [43,46-51]. Consequently, numerous national agencies have recommended arthritis self-management education to complement medical care. Therefore, we piloted a validated stress management program in African American lupus patients and accessed measures of disease activity at critical junctures (e.g., baseline, postintervention, and three months post-intervention) to assess the program's effectiveness in decreasing disease activity and positively impacting various indicators of disease in African American lupus patients.

\section{METHODS}

\subsection{Patients and Entry Criteria}

Patients invited to participate in the Balancing Lupus Experiences with Stress Strategies (BLESS) study were African American systemic lupus erythematosus (SLE) patients attending rheumatology clinics at the Medical University of South Carolina (MUSC). All SLE patients met at least four components of the 1997 ACR revised criteria for SLE [52], were 18 years of age or older, and had not previously participated in a self management program. The total number of individual patients with SLE followed by clinicians at MUSC was 1121 between 2009 and 2012. The total number of new patients with SLE seen by clinicians at MUSC between 2011 and 2012 was 176, of which $61 \%$ were African-American and $88 \%$ were female. Patients invited to participate in the proposed study were SLE patients participating in a longitudinal observational SLE Database at MUSC. There were 402 patients with SLE enrolled in the Database during enrollment in this study. Patients met at least four of the eleven American College of Rheumatology (ACR) Classification Criteria for SLE [52]. Patients in the Database were characterized longitudinally for disease activity and quality of life. The Database is web-based, allowing quick identification of potential participants in clinical studies since, as part of the informed consent process, participants are asked about future re-contact regarding other research studies. MUSC's SLE cohort is geographically diverse, representing more than 60 South Carolina and North Carolina counties. Of the 402 patients with lupus, 336 were African-American, and 218 were Gullah African-American from the Sea Islands of South Carolina and Georgia.

\subsection{Intervention Recruitment and Randomization Procedures}

Eligible patients from within this cohort were invited to participate by a mailed letter that described the study and in person, during regular clinic visits. Interested patients were randomly assigned to the intervention or usual medical care alone. Prior to study participation, subjects completed informed consent documents approved by the 
University of South Carolina (USC) and Medical University of South Carolina (MUSC) Institutional Review Boards.

Experimental group. Intervention activities consisted of six weekly sessions of the "Better Choice, Better Health" Chronic Disease Self-Management Program (CDSMP), developed by Stanford University and also offered in a variety of community settings (e.g., senior centers, churches, hospitals) $[49,53]$. People with different chronic health problems attend together and support one another in making positive changes in their health. Workshops were facilitated by two trained leaders, one or both of whom were non-health professionals with a chronic disease themselves. Subjects covered included: 1) techniques to deal with problems such as frustration, fatigue, pain and isolation, 2) appropriate exercise for maintaining and improving strength, flexibility, and endurance, 3) appropriate use of medications, 4) communicating effectively with family, friends, and health professionals, 5) nutrition, and, 6) how to evaluate new treatments $[43,54]$. It is the process in which the program is taught that makes it effective. Classes are highly participative, and mutual support builds the participants' confidence in their ability to manage their health and maintain active and fulfilling lives $[43,53]$. Weekly sessions lasted approximately two hours and were and administered by trained leaders affiliated with the South Carolina Department of Health and Environmental Control (SCDHEC). Sessions were administered in a group setting with all of the patients randomly assigned to the intervention arm of the study attending the same sessions together. Sessions were scheduled at a location that was familiar to participants at times that were convenient for the entire group and refreshments were provided.

Control group. Control group patients received their usual care with the addition of a mailed book that provided tips for living a healthy life with a chronic condition [55]. Follow up phone calls were made to participants in both study arms in the period between intervention sessions to assess adherence in the intervention group and gauge general study satisfaction in both groups.

\subsection{Measures}

Data collected included demographic (age, sex, etc.), behavioral (healthcare utilization, coping strategies, etc.), and biological (saliva samples for neuroendocrine responses to stress) assessments (findings reported elsewhere). Pre-intervention measures were obtained. Immediately following the six-session intervention phase and then at four months post-intervention, measures were repeated. Those assigned to the control group completed post-intervention follow-up evaluations on the same schedule as those assigned to the experimental group. Specifically to assess disease activity, during each regular clinic visit a history was obtained (including smoking status and use of prednisone, immunosuppressive agents, nonsteroidal anti-inflammatory drugs [NSAIDs], and/or hydroxychloroquine), and physical examination, phlebotomy, and urine collection are performed. SLE Disease Activity Index (SLEDAI) [56,57] and Systemic Lupus International Collaborating Clinics/American College of Rheumatology (SLICC/ACR) Damage Index (SDI) [58] scores were also assessed at each visit. Disease data corresponding with our study data collection timeframes for each participant were extracted from the MUSC SLE Database to be included in analyses. Specific items investigated were 24 specific symptoms of disease activity including weight loss, fatigue, fevers, oral ulcers, malar rash, photosensitivity, vasculitis, other rashes, alopecia, lymphadenopathy, dyspnea, chest pain, Raynaud's phenomenon, abdominal pain, paresthesia, seizures, stroke, memory loss, depression, headaches, myalgias, muscle weakness, arthralgias and joint swelling, along with self-reported flares, captured by a single Patient Global Assessment question about presence and severity of lupus activity in the past month and a single numerical rating of disease activity on a scale of 0 - 10 over the past three months with the 0 anchored by "no activity" and 10 anchored by "most activity”. Self-reported flares did not require a medication change to be included in analyses.

\subsection{Statistical Analyses}

Thirty participants were randomly assigned to intervention and control groups. All participants were African American, 28 were female, and more than half either attended trade school or college (see Table 1 ). Two of the participants assigned to the intervention group did not attend any intervention sessions and were eliminated from all post-intervention analyses. In addition, several participants did not complete post-intervention questionnaires and were also excluded from analyses. Therefore, data were analyzed on 29 participants at baseline $(\mathrm{N}=14$ for control group and $\mathrm{N}=15$ for intervention group), 23 at post-intervention $(\mathrm{N}=11$ for control group and $\mathrm{N}=12$ for intervention group), and 22 at four months post-in-

Table 1. Characteristics of study participants.

\begin{tabular}{ccc}
\hline Characteristic & $\begin{array}{c}\text { Treatment Group } \\
(\mathrm{N}=15)\end{array}$ & $\begin{array}{c}\text { Control Group } \\
(\mathrm{N}=15)\end{array}$ \\
\hline Mean \pm SD age, years & $43.4 \pm 11.7$ & $42.1 \pm 12.3$ \\
No. (\%) African American & $15(100)$ & $15(100)$ \\
No. (\%) female & $14(93)$ & $14(93)$ \\
No. (\%) attended trade school & $2(15)$ & $6(46)$ \\
No. (\%) attended college* & $4(31)$ & $4(31)$ \\
\hline
\end{tabular}

${ }^{*}$ Four participants (two from each group) did not complete information on education level. 
tervention ( $\mathrm{N}=12$ for control group and $\mathrm{N}=10$ for intervention group). "Per-protocol" (or the elimination of any participants that did not complete treatment) rather than "intent-to-treat" (inclusion of all participants regardless of whether they completed treatment) analyses were undertaken due to missing survey data at specified data collection points from most of the excluded participants. Intent-to-treat analyses would have been suitable if excluded participants had completed the study (i.e., provided responses at specified data collection points), even if they did not receive treatments they should have (i.e., completed intervention sessions). Given participant dropout and the investigative nature of this study, statistical tests were deemed inappropriate to assess changes from baseline to post-intervention and at four months post-intervention due to violation of assumptions and low power. Therefore, descriptive statistics of selected disease activity variables at each collection point are reported along with measures of power and correlation. In addition, Cohen's (1988) effect sizes $(d)$ were computed as a measure of power using the software program gpower [59]. Typically, Cohen's $d$ is only reported as a unidirectional statistic ranging from 0 to infinity (typically not above 2 or 3). The magnitude of Cohen's $d$ is similar to that of Pearson's r, wherein a value of 0.2 indicates small effect, 0.5 indicates medium effect, and 0.8 indicates large effect. Reporting Cohen's d was chosen for this study because it is independent of sample size, unlike statistical methods such as t-tests. In this case, effect sizes show the actual magnitude of the difference-not just how likely the results are to have occurred by chance.

\section{RESULTS}

Group differences from baseline to post-intervention. As can be seen in Tables 2 and 3, there were several differences between the intervention and control groups on symptoms pertaining to lupus activity. Many of these differences had large effect sizes. First, when looking at self-reported lupus flares in the past three months, members in the intervention group reported no change from baseline to intervention. To the contrary, participants in the control group reported slightly more lupus flares at

Table 2. Means and standard deviations of systemic lupus disease activity items.

\begin{tabular}{|c|c|c|c|c|c|c|}
\hline \multirow[b]{2}{*}{ Variable } & \multicolumn{2}{|c|}{ Baseline } & \multicolumn{2}{|c|}{ Post-intervention } & \multicolumn{2}{|c|}{4 months } \\
\hline & $\begin{array}{c}\text { Intervention } \\
(\mathrm{N}=15)\end{array}$ & $\begin{array}{c}\text { Control } \\
(\mathrm{N}=14)\end{array}$ & $\begin{array}{c}\text { Intervention } \\
(\mathrm{N}=12)\end{array}$ & $\begin{array}{c}\text { Control } \\
(\mathrm{N}=11)\end{array}$ & $\begin{array}{c}\text { Intervention } \\
(\mathrm{N}=10)\end{array}$ & $\begin{array}{c}\text { Control } \\
(\mathrm{N}=12)\end{array}$ \\
\hline Lupus flare past 3 months & $1.0 \pm 0.5$ & $0.5 \pm 0.5$ & $0.8 \pm 0.7$ & $0.6 \pm 0.5$ & $0.8 \pm 0.6$ & $0.5 \pm 0.5$ \\
\hline Unintended weight loss & $1.4 \pm 1.0$ & $0.6 \pm 0.8$ & $1.2 \pm 0.9$ & $0.7 \pm 0.8$ & $1.5 \pm 1.0$ & $0.7 \pm 0.9$ \\
\hline Fatigue & $2.8 \pm 0.4$ & $1.9 \pm 1.0$ & $2.8 \pm 0.4$ & $2.4 \pm 0.7$ & $2.5 \pm 0.7$ & $2.2 \pm 0.8$ \\
\hline Fevers & $2.3 \pm 0.8$ & $2.4 \pm 0.8$ & $2.1 \pm 0.7$ & $1.8 \pm 0.9$ & $2.2 \pm 0.8$ & $2.1 \pm 1.0$ \\
\hline Sores in mouth or nose & $1.6 \pm 1.1$ & $2.1 \pm 0.8$ & $1.8 \pm 0.8$ & $1.8 \pm 1.0$ & $2.1 \pm 0.7$ & $1.7 \pm 1.0$ \\
\hline Rash on cheeks & $1.6 \pm 1.1$ & $2.0 \pm 1.0$ & $1.8 \pm 0.8$ & $1.7 \pm 1.0$ & $2.0 \pm 0.6$ & $1.8 \pm 1.0$ \\
\hline Other rash & $1.6 \pm 1.1$ & $2.1 \pm 0.8$ & $1.8 \pm 0.8$ & $1.7 \pm 1.0$ & $2.0 \pm 0.6$ & $1.8 \pm 1.0$ \\
\hline Dark blue/purple spots & $1.7 \pm 1.0$ & $2.1 \pm 0.8$ & $2.0 \pm 0.6$ & $1.8 \pm 0.9$ & $2.0 \pm 0.6$ & $2.0 \pm 0.9$ \\
\hline Rash or sick after sun & $1.3 \pm 1.0$ & $1.1 \pm 0.9$ & $1.6 \pm 0.9$ & $1.0 \pm 0.8$ & $1.7 \pm 0.8$ & $1.1 \pm 0.9$ \\
\hline Bald patches, hair loss & $1.4 \pm 0.8$ & $1.3 \pm 0.8$ & $1.6 \pm 0.9$ & $1.0 \pm 0.8$ & $1.7 \pm 0.8$ & $1.6 \pm 1.0$ \\
\hline Shortness of breath & $1.4 \pm 0.9$ & $1.2 \pm 0.8$ & $1.6 \pm 0.9$ & $1.0 \pm 0.9$ & $1.7 \pm 0.8$ & $1.6 \pm 1.0$ \\
\hline Chest pain with deep breath & $2.1 \pm 0.8$ & $1.7 \pm 0.8$ & $2.3 \pm 0.9$ & $2.2 \pm 0.8$ & $2.4 \pm 0.7$ & $1.9 \pm 1.0$ \\
\hline Raynaud's & $0.8 \pm 1.1$ & $0.8 \pm 1.0$ & $0.8 \pm 1.0$ & $0.9 \pm 0.9$ & $1.6 \pm 1.4$ & $0.8 \pm 0.9$ \\
\hline Stomach pain & $2.0 \pm 0.8$ & $1.7 \pm 0.8$ & $2.3 \pm 0.9$ & $2.2 \pm 0.8$ & $2.4 \pm 0.7$ & $1.9 \pm 0.9$ \\
\hline Numbness in arms or legs & $1.5 \pm 1.3$ & $0.9 \pm 1.2$ & $1.3 \pm 1.4$ & $0.9 \pm 1.3$ & $1.6 \pm 1.4$ & $0.9 \pm 1.2$ \\
\hline Seizures & $2.2 \pm 0.9$ & $2.0 \pm 0.0$ & $2.0 \pm 1.0$ & $1.6 \pm 1.1$ & $2.4 \pm 0.5$ & $1.3 \pm 1.4$ \\
\hline Stroke & $1.8 \pm 1.1$ & $1.3 \pm 1.1$ & $1.7 \pm 1.1$ & $1.5 \pm 0.9$ & $1.9 \pm 1.0$ & $1.8 \pm 1.2$ \\
\hline Forgetfulness & $1.3 \pm 0.6$ & $0.9 \pm 0.5$ & $1.5 \pm 0.7$ & $1.1 \pm 0.8$ & $1.2 \pm 0.9$ & $0.8 \pm 0.6$ \\
\hline Feeling depressed & $1.3 \pm 1.3$ & $0.7 \pm 0.9$ & $1.2 \pm 1.1$ & $0.9 \pm 1.0$ & $0.7 \pm 1.3$ & $0.6 \pm 0.9$ \\
\hline Headaches & $0.4 \pm 0.6$ & $0.5 \pm 0.5$ & $0.6 \pm 0.7$ & $0.5 \pm 0.5$ & $0.8 \pm 0.6$ & $0.4 \pm 0.7$ \\
\hline Muscle pain & $1.9 \pm 1.0$ & $1.5 \pm 0.9$ & $2.3 \pm 0.9$ & $2.2 \pm 0.8$ & $2.4 \pm 0.7$ & $1.9 \pm 0.9$ \\
\hline Muscle weakness & $1.0 \pm 0.8$ & $0.5 \pm 0.7$ & $1.2 \pm 0.9$ & $0.8 \pm 0.6$ & $1.4 \pm 0.7$ & $0.8 \pm 1.0$ \\
\hline Swelling in joints & $1.1 \pm 0.9$ & $0.6 \pm 0.9$ & $1.1 \pm 0.9$ & $0.9 \pm 0.5$ & $1.2 \pm 0.9$ & $0.7 \pm 0.9$ \\
\hline Disease activity past 3 months & $6.0 \pm 2.8$ & $4.3 \pm 1.9$ & $5.3 \pm 2.6$ & $5.6 \pm 2.1$ & $6.7 \pm 2.2$ & $6.3 \pm 2.1$ \\
\hline
\end{tabular}


Table 3. Mean difference scores between baseline and post-intervention by group.

\begin{tabular}{|c|c|c|c|c|c|c|}
\hline \multirow{2}{*}{ Variable } & \multicolumn{3}{|c|}{ Post-intervention $^{*}(\mathrm{~N}=23)$} & \multicolumn{3}{|c|}{4 months $^{*}(\mathrm{~N}=23)$} \\
\hline & $M_{\text {int }}$ & $M_{\text {con }}$ & $d$ & $M_{\text {int }}$ & $M_{\text {con }}$ & $d$ \\
\hline Lupus flare past 3 months & 0.00 & 0.13 & 0.22 & -0.10 & 0.11 & 0.65 \\
\hline Unintended weight loss & 0.00 & 0.10 & 0.10 & 0.10 & 0.00 & 0.08 \\
\hline Fatigue & 0.09 & 0.50 & 0.53 & -0.27 & 0.10 & 0.54 \\
\hline Fevers & -0.08 & -0.44 & 0.44 & -0.09 & -0.30 & 0.22 \\
\hline Sores in mouth or nose & 0.42 & -0.30 & 0.90 & 0.55 & -0.55 & 1.02 \\
\hline Rash on cheeks & 0.42 & -0.10 & 0.63 & 0.46 & -0.18 & 0.56 \\
\hline Other rash & 0.42 & -0.30 & 0.90 & 0.46 & -0.36 & 0.80 \\
\hline Dark blue/purple spots & 0.46 & -0.20 & 0.83 & 0.20 & -0.30 & 0.57 \\
\hline Rash or sick after sun & 0.33 & -0.10 & 0.37 & 0.27 & 0.40 & 0.11 \\
\hline Bald patches, hair loss & 0.18 & -0.20 & 0.38 & 0.10 & 0.27 & 0.21 \\
\hline Swollen glands in neck & 0.27 & -0.30 & 0.56 & 0.20 & 0.18 & 0.02 \\
\hline Shortness of breath & 0.50 & -0.14 & 0.76 & 0.00 & 0.20 & 0.20 \\
\hline Chest pain with deep breath & 0.17 & 0.50 & 0.45 & 0.36 & 0.46 & 0.11 \\
\hline Raynaud's & -0.09 & -0.10 & 0.01 & 0.20 & -0.18 & 0.45 \\
\hline Stomach pain & 0.27 & 0.50 & 0.34 & 0.50 & 0.46 & 0.05 \\
\hline Numbness in arms or legs & 0.00 & 0.30 & 0.18 & 0.09 & 0.22 & 0.08 \\
\hline Seizures & -0.17 & -0.50 & 0.29 & 0.00 & -0.91 & 0.84 \\
\hline Stroke & -0.08 & 0.30 & 0.38 & 0.09 & 0.55 & 0.26 \\
\hline Forgetfulness & 0.25 & 0.30 & 0.05 & -0.09 & -0.09 & 0.00 \\
\hline Feeling depressed & 0.08 & 0.10 & 0.02 & -0.27 & -0.36 & 0.08 \\
\hline Headaches & 0.20 & 0.22 & 0.03 & 0.46 & 0.00 & 0.61 \\
\hline Muscle pain & 0.33 & 0.80 & 0.64 & 0.55 & 0.73 & 0.21 \\
\hline Muscle weakness & 0.25 & 0.40 & 0.17 & 0.46 & 0.46 & 0.00 \\
\hline Pain or stiffness in joints & 0.17 & 0.80 & 0.82 & 0.36 & 0.73 & 0.46 \\
\hline Swelling in joints & 0.25 & 0.18 & 0.16 & 0.09 & 0.33 & 0.59 \\
\hline Disease activity past 3 months & -0.75 & 1.00 & 0.66 & 0.55 & 2.36 & 0.68 \\
\hline
\end{tabular}

${ }^{*} M_{\text {int }}=$ mean difference in intervention group; $M_{\text {con }}=$ mean difference in control group; $d=$ Cohen's $d$.

post-intervention. In assessing overall disease activity during the past three months, participants in the intervention group reported less disease activity at post-intervention than at baseline, while participants in the control group reported more disease activity $(d=0.66)$.

Despite the overall disease assessments improving from baseline to post-intervention in the intervention group, many specific symptoms improved in the control group. More specifically, large effect sizes were witnessed between the control and intervention groups pertaining to the following symptoms: sores in the mouth or nose $(d=$ $0.90)$, rash on cheeks $(d=0.63)$, other rashes $(d=0.90)$, dark blue or purple spots $(d=0.83)$, and shortness of breath $(d=0.76)$. With all these variables, individuals in the control group reported decreases in symptomatology while individuals in the intervention group reported increases.

There were a couple of specific symptoms in which participants in the intervention group exhibited better outcomes at post-intervention than participants in the control group when compared to baseline. When looking at muscle pain and pain or stiffness in joints, although both groups had increases in reported symptoms between baseline and post-intervention, participants in the intervention group had lesser increases $(d=0.64$ and 0.82 , respectively).

Group differences from baseline to post-post intervention. Most of the differences in lupus disease activity from baseline to four months post-intervention (post-post intervention) were consistent with those from baseline to post-intervention. As can be seen in Table 3, the control group continued to report improvements pertaining to the following symptoms: sores in mouth or nose, rash on cheeks, other rash, and dark blue or purple spots. In addition, members in the control group reported decreases in seizures between baseline and post-post intervention while participants in the intervention group reported no change $(d=0.84)$. Still, individuals in the intervention group reported a decrease in lupus flares and participants in the control group reported an increase $(d=0.65)$. Likewise, participants in the intervention group reported lesser increases in overall disease activity compared to 
controls $(d=0.68)$.

Correlations between baseline and post-intervention. Correlations were examined between baseline and postintervention pertaining to lupus symptoms that had at least a moderate effect size $(d \geq 0.60)$. Overall disease activity questions (e.g., lupus flares and disease activity) were also assessed. While there were no strong associations between intervention or control group and symptomatology, as can be seen in Table 4, all variables examined (except for lupus flares) had moderate relations.

\section{DISCUSSION}

This pilot demonstrated that a validated chronic disease self-management program to support and assist participants in finding practical ways to deal with pain, fatigue, and stress, as well as introduce better nutrition and exercise choices, new treatment options, and better ways to talk with doctors and family about health matters could improve indicators of disease activity in African American lupus patients. The intervention resulted in significant improvement in frequency of self-reported lupus flares, muscle pain and pain or stiffness in joints immediately following intervention activities and four months post-intervention. Overall, the control group reported slightly more lupus flares at post-intervention, while participants in the intervention group reported less disease activity at post-intervention than at baseline.

Specifically, participants in the intervention group exhibited better outcomes at post-intervention than participants in the control group in the areas of muscle pain and pain or stiffness in joints. Literature has shown that pain has been frequently reported as an unmet need by African American lupus patients [60], so future intervention efforts should target strategies for sustaining positive health outcomes that have been observed in other areas [54]. Additionally, from baseline to four months postintervention, individuals in the intervention group reported a decrease in lupus flares and participants in the control group reported an increase. Likewise, participants in the intervention group reported lesser increases in overall disease activity compared to controls.

Overall, our results confirm findings from research done by other investigators, and support the importance of such an intervention. A large body of evidence has shown that health-promoting programs in stress management have resulted in short-term improvement in pain, psychological function, and perceived physical function among persons with SLE [37,45,49]. Additionally, psychoeducation [44] and graded aerobic exercise [61] have been shown to be useful in the management of fatigue. Although there is no generally accepted self-management program available for SLE [43], the Chronic Disease Self-Management Program (CDSMP) adapted for this pilot has demonstrated significant improvements in health distress, self-reported global health, and activity limitation, with trends toward improvement in self efficacy and mental stress management [53].

\section{LIMITATIONS}

Given that this study was an exploratory pilot, the small sample size will reduce generalizability of the results. However, since Cohen's $d$ is a measure of the magnitude of the effect irrespective of sample size, we would expect a larger sample to improve the odds of significance, but would also expect the magnitude of the relationship to remain the same. Therefore, our results are still impressive in the domain of disease activity. In spite of a limited sample size, our findings fill a critical gap left by similar investigations that have not been racially representative. This study clearly demonstrates that comparable interventions may be effective or even more effective in more racially diverse populations. Additionally, our intervention was multi-faceted and combined elements of efficacy enhancement and problem solving. With our design, we cannot definitively separate the effects of each element. Further research with larger sam-

Table 4. Correlation matrix of difference scores between baseline and post-intervention for selected variables.

\begin{tabular}{|c|c|c|c|c|c|c|c|c|c|c|}
\hline & 1 & 2 & 3 & 4 & 5 & 6 & 7 & 8 & 9 & 10 \\
\hline 1. Group (intervention or control) & - & & & & & & & & & \\
\hline 2. Lupus flare past 3 months & -0.10 & - & . & & & & & & & \\
\hline 3. Sores in mouth or nose & $0.42^{*}$ & -0.11 & - & & & & & & & \\
\hline 4. Rash on cheeks & 0.31 & -0.12 & $0.88^{* *}$ & - & & & & & & \\
\hline 5. Other rash & & $0.42^{*}$ & -0.11 & $1.0^{* *}$ & $0.88^{* *}$ & - & & & & \\
\hline 7. Shortness of breath & 0.36 & -0.03 & 0.32 & 0.32 & 0.32 & 0.32 & - & & & \\
\hline 8. Muscle pain & & -0.32 & 0.40 & 0.14 & 0.06 & 0.14 & 0.19 & -0.29 & - & \\
\hline 9. Pain or stiffness in joints & -0.40 & 0.38 & 0.14 & 0.08 & 0.14 & 0.19 & -0.29 & $0.85^{* *}$ & - & \\
\hline 10. Disease activity past 3 months & -0.32 & $0.64^{* *}$ & -0.02 & -0.02 & -0.02 & -0.01 & 0.04 & $0.47^{*}$ & $0.52^{*}$ & \\
\hline
\end{tabular}

${ }^{*} p<0.05 .{ }^{* *} p<0.01$. 
ples that are racially representative and can be randomized into varying levels and elements of intervention is recommended to determine which kinds of programs work best, for which kinds of patients, and in which situations.

\section{CONCLUSION}

In summary, our pilot stress intervention improved indicators of disease activity in an understudied group. African American patients with SLE experienced significant improvement in frequency of lupus flares, muscle pain and pain or stiffness in joints. Our findings imply that comparable, if not more significant, gains in relevant health indicators are possible in African American patients when provided the opportunity to participate in such an intervention. This widely available intervention has the potential to reduce health problems and costs in a debilitating, management-intensive chronic disease in the population subset at the highest risk for the disease and should be more widely implemented and studied for more rigorously assess benefits.

\section{ACKNOWLEDGEMENTS}

This research was made possible through a 2010-2012 Pfizer Fellowship in Health Disparities from Pfizer's Medical and Academic Partnership Program. The project described was also supported by Award number UL1RR029882 from the National Center for Research Resources, the Medical University of SC Clinical and Translational Science Award [grant number UL1TR000062, formerly U54RR026107], the Division of Rheumatology and Immunology Multidisciplinary Clinical Research Center [grant number P60AR062755], and National Institutes of Health and the Ralph H. Johnson VAMC Medical Research Service.

\section{REFERENCES}

[1] Ward, M.M., Pyun, E. and Studenski, S. (1995) Causes of death in systemic lupus erythematosus. Long-term followup of an inception cohort. Arthritis \& Rheumatism, 38, 1492-1499. http://dx.doi.org/10.1002/art.1780381016

[2] Trager, J. and Ward, M.M. (2001) Mortality and causes of death in systemic lupus erythematosus. Current Opinion in Rheumatology, 13, 345-351.

http://dx.doi.org/10.1097/00002281-200109000-00002

[3] Urowitz, M.B., Gladman, D.D., Abu-Shakra, M. and Farewell, V.T. (1997) Mortality studies in systemic lupus erythematosus. Results from a single center. III. Improved survival over 24 years. Journal of Rheumatology, 24, 1061-1065.

[4] Urowitz, M.B., Feletar, M., Bruce, I.N., Ibanez, D. and Gladman, D.D. (2005) Prolonged remission in systemic lupus erythematosus. Journal of Rheumatology, 32, 14671472.

[5] Heinlen, L.D., McClain, M.T., Merrill, J., et al. (2007) Clinical criteria for systemic lupus erythematosus precede diagnosis, and associated autoantibodies are present be- fore clinical symptoms. Arthritis \& Rheumatism, 56, 2344-2351. http://dx.doi.org/10.1002/art.22665

[6] Uramoto, K.M., Michet Jr., C.J., Thumboo, J., Sunku, J., O'Fallon, W.M. and Gabriel, S.E. (1999) Trends in the incidence and mortality of systemic lupus erythematosus, 1950-1992. Arthritis \& Rheumatism, 42, 46-50.

http://dx.doi.org/10.1002/1529-0131(199901)42:1<46::AI D-ANR6>3.0.CO;2-2

[7] Gabriel, S. and Michaud, K. (2009) Epidemiological studies in incidence, prevalence, mortality, and comorbidity of the rheumatic diseases. Arthritis Research \& Therapy, 11, 229. http://dx.doi.org/10.1186/ar2669

[8] Demas, K.L. and Costenbader, K.H. (2009) Disparities in lupus care and outcomes. Current Opinion in Rheumatology, 21, 102-109.

http://dx.doi.org/10.1097/BOR.0b013e328323daad

[9] Askanase, A., Shum, K. and Mitnick, H. (2012) Systemic lupus erythematosus: An overview. Social Work in Health Care, 51, 576-586. http://dx.doi.org/10.1080/00981389.2012.683369

[10] Gabba, A., Piga, M., Vacca, A., et al. (2012) Joint and tendon involvement in systemic lupus erythematosus: An ultrasound study of hands and wrists in 108 patients. Rheumatology, 51, 2278-2285. http://dx.doi.org/10.1093/rheumatology/kes226

[11] Torrente-Segarra, V., Lisbona, M.P., Rotés-Sala, D., et al. (2012) Hand and wrist arthralgia in systemic lupus erythematosus is associated to ultrasonographic abnormalities. Joint Bone Spine, 80, 402-406.

[12] Beckerman, N.L., Auerbach, C. and Blanco, I. (2011) Psychosocial dimensions of SLE: Implications for the health care team. Journal of Multidisciplinary Healthcare, 4, 63-72. http://dx.doi.org/10.2147/JMDH.S19303

[13] Wallace, D. (2000) The lupus book. New York Oxford University Press.

[14] Roman, M.J., Shanker, B.-A., Davis, A., et al. (2003) Prevalence and correlates of accelerated atherosclerosis in systemic lupus erythematosus. New England Journal of Medicine, 349, 2399-2406. http://dx.doi.org/10.1056/NEJMoa035471

[15] Kulczycka, L., Sysa-Jedrzejowska, A. and Robak, E. (2010) Quality of life and satisfaction with life in SLE patients-The importance of clinical manifestations. Clinical Rheumatology, 29, 991-997. http://dx.doi.org/10.1007/s10067-010-1509-0

[16] Bachen, E.A., Chesney, M.A. and Criswell, L.A. (2009) Prevalence of mood and anxiety disorders in women with systemic lupus erythematosus. Arthritis Care \& Research, 61, 822-829. http://dx.doi.org/10.1002/art.24519

[17] Jarpa, E., Babul, M., Calderón, J., et al. (2011) Common mental disorders and psychological distress in systemic lupus erythematosus are not associated with disease activity. Lupus, 20, 58-66. http://dx.doi.org/10.1177/0961203310381773

[18] Danoff-Burg, S. and Friedberg, F. (2009) Unmet needs of patients with systemic lupus erythematosus. Behavioral Medicine, 35, 5-13.

http://dx.doi.org/10.3200/BMED.35.1.5-13 
[19] Dobkin, P.L., Fortin, P.R., Joseph, L., Esdaile, J.M., Danoff, D.S. and Clarke, A.E. (1998) Psychosocial contributors to mental and physical health in patients with systemic lupus erythematosus. Arthritis \& Rheumatism, 11, 23-31. http://dx.doi.org/10.1002/art.1790110105

[20] Seawell, A.H. and Danoff-Burg, S. (2004) Psychosocial research on systemic lupus erythematosus: A literature review. Lupus, 13, 891-899. http://dx.doi.org/10.1191/0961203304lu1083rr

[21] Ward, M.M. and Studenski, S. (1990) Clinical manifestations of systemic lupus erythematosus: Identification of racial and socioeconomic influences. Archives of Internal Medicine, 150, 849-853.

http://dx.doi.org/10.1001/archinte.1990.00390160099020

[22] Petri, M., Perez-Gutthann, S., Longenecker, J.C. and Hochberg, M. (1992) Morbidity of systemic lupus erythematosus: Role of race and socioeconomic status. $\mathrm{Pe}$ diatric Nephrology, 6, 406-406. http://dx.doi.org/10.1007/BF00869752

[23] Alarcón, G.S., Roseman, J., Bartolucci, A.A., et al. (1998) Systemic lupus erythematosus in three ethnic groups: II. Features predictive of disease activity early in its course. Arthritis \& Rheumatism, 41, 1173-1180. http://dx.doi.org/10.1002/1529-0131(199807)41:7<1173:: AID-ART5>3.0.CO;2-A

[24] Uribe, A., Graciela, S., Alarcon, G., et al. (2004) Systemic lupus erythematosus in three ethnic groups. XVIII. Factors predictive of poor compliance with study visits. Arthritis \& Rheumatism, 51, 258-263. http://dx.doi.org/10.1002/art.20226

[25] Bernatsky, S., Boivin, J.F., Joseph, L., et al. (2005) Race/ ethnicity and cancer occurrence in systemic lupus erythematosus. Arthritis \& Rheumatism, 53, 781-784. http://dx.doi.org/10.1002/art.21458

[26] Alarcon, G.S., Beasley, T.M., Roseman, J.M., et al. (2005) Ethnic disparities in health and disease: The need to account for ancestral admixture when estimating the genetic contribution to both (LUMINA XXVI). Lupus, 14, 867868. http://dx.doi.org/10.1191/0961203305lu2184xx

[27] Alarcon, G.S., McGwin Jr., G., Petri, M., et al. (2006) Time to renal disease and end-stage renal disease in PROFILE: A multiethnic lupus cohort. PLOS Medicine, 3, e396. http://dx.doi.org/10.1371/journal.pmed.0030396

[28] Webb, R., Kelly, J.A., Somers, E.C., Hughes, T., Kaufman, K.M., Sanchez, E., Nath, S.K., Bruner, G., AlarconRiquelme, M.E., Gilkeson, G.S., Kamen, D.L., Richardson, B.C., Harley, J.B. and Sawalha, A.H. (2011) Early disease onset is predicted by a higher genetic risk for lupus and is associated with a more severe phenotype in lupus patients. Annals of the Rheumatic Diseases, 70, 151-156. http://dx.doi.org/10.1136/ard.2010.141697

[29] McCarty, D.J., Manzi, S., Medsger Jr., T.A., RamseyGoldman, R., LaPorte, R.E. and Kwoh, C.K. (1995) Incidence of systemic lupus erythematosus. Race and gender differences. Arthritis \& Rheumatism, 38, 1260-1270. http://dx.doi.org/10.1002/art.1780380914

[30] Cooper, G.S., Parks, C.G., Treadwell, E.L., et al. (2002) Differences by race, sex and age in the clinical and immunologic features of recently diagnosed systemic lupus erythematosus patients in the southeastern United States. Lupus, 11, 161-167.

http://dx.doi.org/10.1191/0961203302lu161oa

[31] Williams, D. (2003) The health of men: Structured inequalities and opportunities. American Journal of Public Health, 93, 724-731. http://dx.doi.org/10.2105/AJPH.93.5.724

[32] Wyatt, S., Williams, D., Calvin, R., Henderson, F., Walker, E. and Winters, K. (2003) Racism and cardiovascular disease in African-Americans. American Journal of Medical Sciences, 325, 315-331. http://dx.doi.org/10.1097/00000441-200306000-00003

[33] Carroll, G. (1998) Mundane extreme environmental stress and African-American families: A case for recognizing different realities. Journal of Comparative Family Studies, 29, 271.

[34] Hertzman, C. and Wiens, M. (1996) Child development and long-term outcomes: a population health perspective and summary of successful interventions. Social Science \& Medicine, 43, 1083-1095. http://dx.doi.org/10.1016/0277-9536(96)00028-7

[35] Williams, D.R.C.C. (2001) Racial residential segregation-A fundamental cause of racial disparities in health. Public Health Reports, 116, 404-416.

[36] Cattell, V. (2001) Poor people, poor places, and poor health: The mediating role of social networks and social capital. Social Science \& Medicine, 52, 1501-1516. http://dx.doi.org/10.1016/S0277-9536(00)00259-8

[37] O’Donnell, M. (2004) Health-promotion behaviors that promote self healing. The Journal of Alternative and Complementary Medicine, 10, S49-S60. http://dx.doi.org/10.1089/1075553042245809

[38] Gaab, J., Sonderegger, L., Scherrer, S. and Ehlert, U. (2006) Psychoneuroendocrine effects of cognitive-behavioral stress management in a naturalistic setting-A randomized controlled trial. Psychoneuroendocrinology, 31, 428-438. http://dx.doi.org/10.1016/j.psyneuen.2005.10.005

[39] Greco, C.M., Rudy, T.E. and Manzi, S. (2004) Effects of a stress-reduction program on psychological function, pain, and physical function of systemic lupus erythematosus patients: A randomized controlled trial. Arthritis Care \& Research, 51, 625-634. http://dx.doi.org/10.1002/art.20533

[40] Dobkin, P., Da Costa, D., Joseph, L., et al. (2002) Counterbalancing patient demands with evidence: Results from a pan-Canadian randomized clinical trial of brief supportive-expressive group psychotherapy for women with systemic lupus erythematosus. Annals of Behavioral Medicine, 24, 88-99. http://dx.doi.org/10.1207/S15324796ABM2402_05

[41] Bijlani, R., Vempati, R., Yadav, R., et al. (2005) A brief but comprehensive lifestyle education program based on yoga reduces risk fractors for cardiovascular disease and diabetes mellitus. Journal of Alternative and Complementary Medicine, 11, 267-274. http://dx.doi.org/10.1089/acm.2005.11.267

[42] Coalition, T.W.L. (2005) Sisters! Understand your Heart, Body, \& Environment. Spring Luncheon. State University of New York at Buffalo, Buffalo. 
[43] Lorig, K., Ritter, P.L. and Plant, K. (2005) A disease-specific self-help program compared with a generalized chronic disease self-help program for arthritis patients. Arthritis Care \& Research, 53, 950-957. http://dx.doi.org/10.1002/art.21604

[44] Karlson, E., Liang, M., Eaton, H., Huang, J., Fitzgerald, L., Rogers, M.P. and Daltroy, L.H. (2004) A randomized clinical trial of psychoeducational intervention to improve outcomes in systemic lupus erythematosus. Arthritis \& Rheumatism, 50, 1832-1841. http://dx.doi.org/10.1002/art.20279

[45] Greco, C., Rudy, T. and Manzi, S. (2004) Effects of a stress-reduction program on psychological function, pain, and physical function of systemic lupus erythematosus patients: A randomized controlled trial. Arthritis Care \& Research, 51, 625-634. http://dx.doi.org/10.1002/art.20533

[46] Barlow, J.H., Turner, A.P. and Wright, C.C. (2000) A randomized controlled study of the arthritis self-management program in the UK. Health Education and Research, 15, 665-680. http://dx.doi.org/10.1093/her/15.6.665

[47] Brady, T.J., Kruger, J., Helmick, C.G., Callahan, L.F. and Boutaugh, M.L. (2003) Intervention programs for arthritis and other rheumatic diseases. Health Education \& Behavior, 30, 44-63. http://dx.doi.org/10.1177/1090198102239258

[48] Lorig, K., Lubeck, D., Kraines, R.G., Seleznick, M. and Holman, H.R. (1985) Outcomes of self-help education for patients with arthritis. Arthritis \& Rheumatism, 28, 680685. http://dx.doi.org/10.1002/art.1780280612

[49] Lorig, K. and Holman, H.R. (1993) Arthritis Self-Management Studies: A twelve-year review. Health Education Quarterly, 20, 17-28. http://dx.doi.org/10.1177/109019819302000104

[50] Lorig, K., Mazonson, P.D. and Holman, H.R. (1993) Evidence suggesting that health education for self-management in patients with chronic arthritis has sustained health benefits while reducing health care costs. Arthritis \& Rheumatism, 36, 27-34.

[51] Kruger, J., Helmick, C.G., Callahan, L.F. and Haddix, A.C. (1998) Cost-effectiveness of the arthritis self-help course. JAMA Internal Medicine, 158, 1245-1249. http://dx.doi.org/10.1001/archinte.158.11.1245

[52] Hochberg, M.C. (1997) Updating the American college of rheumatology revised criteria for the classification of systemic lupus erythematosus. Arthritis \& Rheumatism, 40, 1725. http://dx.doi.org/10.1002/art.1780400928

[53] Lorig, K., Sobel, D. and Stewart, A. (1999) Evidence suggesting that a chronic disease self-management program can improve health status while reducing utilization and costs: A randomized trial. Medical Care, 37, 5-14. http://dx.doi.org/10.1097/00005650-199901000-00003

[54] Lorig, K., Mazonson, P. and Holman, H. (1993) Evidence suggesting that health education for self-management in patients with chronic arthritis has sustained health benefits while reducing health care costs. Arthritis \& Rheumatism, 36, 439-446. http://dx.doi.org/10.1002/art.1780360403

[55] Lorig, K., Sobel, D., Gonzalez, V. and Minor, M. (2008) Living a healthy life with chronic conditions: Self management of heart disease, arthritis, diabetes, asthma, bronchitis, emphysema and others. Bull Publishing Company.

[56] Brunner, H., Feldman, B., Bombardier, C. and Silverman, E. (1999) Sensitivity of the systemic lupus erythematosus disease activity index, British isles lupus assessment group index, and systemic lupus activity measure in the avaluation of clinical change in childhood-onset systemic lupus erythematosus. Arthritis \& Rheumatism, 42, 1354 1360. http://dx.doi.org/10.1002/1529-0131(199907)42:7< 1354::AID-ANR8>3.0.CO;2-4

[57] Churg, J. and Sobin, L. (1992) Renal disease: Classification and atlas of glomerular diseases. IgakuShoin, Tokyo.

[58] Dayal, N.A., Gordon, C., Tucker, L. and Isenberg, D.A. (2002) The SLICC damage index: Past, present and future. Lupus, 11, 261-265.

[59] Cohen, J. (1988) Statistical power analysis for the behavioral sciences. Revised Edition, Academic Press, New York.

[60] Danoff-Burg, S. and Friedberg, F. (2009) Unmet needs of patients with systemic lupus erythematosus. Behavioral Medicine, 35, 5-13. http://dx.doi.org/10.3200/BMED.35.1.5-13

[61] Tench, C., McCarthy, J., McCurdie, I., White, P. and D'Cruz, D. (2003) Fatigue in systemic lupus erythematosus: A randomized controlled trial of exercise. Rheumatology, 42, 1050-1054. http://dx.doi.org/10.1093/rheumatology/keg289 